\title{
Autologous Interferon-producing Killer Dendritic Cells
}

National Cancer Institute

\section{Source}

National Cancer Institute. Autologous Interferon-producing Killer Dendritic Cells. NCI

Thesaurus. Code C125667.

A preparation of autologous dendritic cells (DC) with a molecular expression profile similar to both natural killer (NK) cells and DCs, with potential antineoplastic activity. Autologous interferon-producing killer dendritic cells (IKDCS) are characterized by doublenegative expression of CD3 and CD19; these cells also express low levels of CD11 and are positive for B220. They are disting uished from plasmacytoid DCs (pDCs) by the absence of lymphocyte antigen 6C (Ly6C, Gr-1) expression. IKDCs produce interferon gamma (IFN-gamma) and interleukin (IL) -12, and are able to kill typical NK target cells using NK receptors while retaining DC-like antigen-presenting activity. Upon administration of the autologous IKDCs, these cells secrete high levels of IFN-gamma and, when in contact with tumor cells, mediate TNF-related apoptosis-inducing lig and (TRAIL)-dependent direct lysis of tumor cells. The resulting apoptotic tumor antigens may be presented by the IKDCs, thus activating the immune system to exert a cytotoxic T-lymphocyte (CTL) response to further eliminate tumor cells. 